\title{
Diversity - A Strategic Imperative Or A Basic Business Requirement? A Proposed Taxonomy
}

Kenneth R. Tillery, Ph.D., Middle Tennessee State University, USA Arthur L. Rutledge, Ph.D., Mercer University, USA

\begin{abstract}
A Taxonomy of Diversity is developed to examine the connection between diversity and strategy. Academic and popular management literatures, as well as the popular press, promulgate the idea that social diversity is a strategic imperative for success in business. This paper presents a taxonomy of social diversity, defines its variables and examines their potential use as a source of a competitive advantage in the formulation of business strategy. Six types of diversity are definedDe jure Diversity, De facto Diversity, Market Driven Diversity, Skill Driven Diversity, Cost Driven Diversity, and Ethics Driven Diversity.
\end{abstract}

Keywords: Diversity, strategic imperative, taxonomy, competitive advantage

"Oh if I but could have foreseen the changes nature has wrought; that within me and that which surrounds. I recognize naught the desires and demands levied now upon me by the minions. It is mine own undoing having cast such choices aside, seeing only my own path to the end desired. I am lost, alone, unlike the others. Would that I could see myself in their eyes, my fate rejoined to lead all to glory in success." (Anon.)

\section{INTRODUCTION}

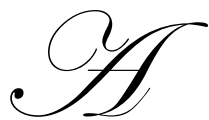

common call today continues to resonate for an expansive inclusion of the multiple ethnic, cultural and other identifiable minority groupings into the general social and economic communities of the USA. This calling exists at both a micro and macro level. At the macro level the arguments are often focused on such socio-political issues as to what constitutes a "diverse group", how do they attain standing, should all be allowed to come in (enter the USA), what service or protection is to be provided, how to control and contain the myriad impacts on the social fabric of the country. The overarching consideration is from the legal perspective. At the micro level this "diversity" discussion revolves around two lines of action. The first is how a firm addresses and rethinks the incorporation of these identifiable groupings into the markets sought and served. The second is how "diversity" is to be incorporated into the organizational fabric in terms of workforce composition. From the strategic perspective these are complementary facets, drawing together the internal and external environments of the firm. To assess whether or not diversity can be a primary underpinning in the creation of a strategy, we need an understanding of what a strategy is and does. To understand if diversity is a strategic imperative or just a part of the strategy, we must examine what diversity is and means in the business sense. The question as to whether or not diversity itself becomes an imperative to all firms (thus a basic business requirement) or is just one of many variables to a competitive positioning of the firm will be addressed in this paper.

\section{STRATEGY AND DIVERSITY}

Strategy is an oft used and misused term. Multiple meanings have been given and used. [Hitt et al 2007, Mintzberg 1987, Porter, 1996] Strategy is at the top hierarchy of planning and provides the goal determination and supportive actions necessary for their accomplishment. It is an incorporation and iterative use of the environmental factors, opportunities, threats and driving forces, connecting the market with the capacity (resources) of the firm to produce and provide a desired output. For the firm a proactive strategy created is one of positioning and aligning 
itself with the served market.

Strategy can also be seen as a perspective and as such "... raises the issue of how intentions diffuse through a group of people to become shared as norms and values". [Mintzberg 1987] In this we must consider the differences of such values and norms associated with diversity and their strategic implications in the creation and provision of the product/service to the market. How are the diverse values (and skills) of the workforce integrated to pursue the common purpose of the organization? Do such differences hinder or help; are they strengths or weaknesses or both in the development of a competitive strategy? Are they or can they become the competencies and capabilities the firm needs to establish the basis of competitive advantage?

Diversity is also a broadly conceptualized term, used in multiple ways. [Mujtaba et al 2009; Harrison et al 1998, Solomon 1994] It can be used to categorize differences in thought, actions, beliefs, value sets, needs as well as groupings codified by race, gender, age, skin-color, educational levels or other attributes. This is not an all inclusive listing or breakout. It serves only to illustrate a range of characteristics used to separate. Diversity as a term is nonjudgmental; it is value neutral. It is when decisions and actions are made and taken on the basis of such differences that diversity can take on a value laden meaning.

Numerous searches were performed on preeminent management literature databases using the key word combinations of strategy and diversity, diversity and classification, and diversity and taxonomy. While there were multiple references connecting diversity and strategy, the preponderance focused on incorporation along the race, gender attributes. No taxonomies related to strategy and/or strategic management of diversity were discovered. Therefore, the following Taxonomy has been constructed to allow for the examination of the Diversity - Strategy connection along other classifications.

\section{VIEWS OF DIVERSITY - TAXONOMY OF STRATEGIC SOCIAL DIVERSITY}

The connection of diversity and strategy can be made in a number of ways. Each of the following models offer insights to the role and impact diversity plays as a driving force or a basis (source) of competitive advantage in the formulation and implementation of a firm's strategy.

\section{Market Driven Diversity}

Firms marketing to the broad customer group will seek to sell to the many often. From a customer view, diversity offers a source of revenue from a marketplace that is identifiably wide and deep. As a revenue source it is to be mined and developed. The search is to find the ways to make the product/service appealing to the specific buying patterns within the large diverse market segment. The focus is that of differentiation, inclusiveness and cost. Examples of this approach can be seen in the marketing and product line of most major manufacturing corporations in durable and consumer goods. On the grocery shelves look at the varieties of personal cleaning products of soaps and creams. It is also visible in the higher tech products of mass communications (cell phones).

For firms servicing a more limited market, the more apparent markings of diversity limiting inclusiveness will be sought. Here, the firm is not after a widely diverse group, but the unique component within the market providing a more, not less discriminating view of product use or selection. The ability to match the buying determinants with the specific group is as crucial here as with the large diverse market. The group itself may be diverse in other categorizing terms but is exclusive with regard to the acquisition decision and or use of the product or service. Luxury items such as jewelry (Tiffany) and exclusively provided services (resorts and spas) are examples.

Thus Market Driven diversity is keyed to the psychological buying determinants which allow or provide for separation and regroupings along the more common identifiers of diversity. Market driven diversity is outwardly focused. 


\section{Skill Driven Diversity}

Skill Driven diversity is internally focused. Skill driven diversity looks at diversity in terms of the labor force knowledge and expertise required to generate and provide the product/service. By definition, diverse groups possess some level of views, attitudes, and skills which are not present in other groupings. The basic question asked is, are these differences required to meet the purpose of the firm in a competitive manner? If not, there is little support to add such variation to the processes used, or to disrupt the existing firm "culture". Much has been written about removing the sources of variation in the work flow through design and training. The emphasis is on adding value across the transformation cycle, controlling (minimizing) cost and creating some basis of differentiation for the customer.

This often leads to the narrowing in skill diversity associated within organizational groupings in the product generation. Diversity certainly brings information richness to the decision-making process within the firm. This richness should lead to better decisions. However, diversity may slow down critical decision-making and planning processes if not instituted and managed properly. So, even if better decisions are made, they may be overcome by events due to their tardiness. Taiichi Ohno [1990], father of the Just-In-Time (JIT) management philosophy, partially attributes Japanese success over USA companies to the ability of Japanese managers and workers to come to a consensus more rapidly than their USA counterparts. He credits this to the fact that the Japanese workforce is more homogeneous. Thus the limitation of diversity along one dimension may counterbalance the benefits of diversity from other sources. However, if such differences are needed to provide greater effectiveness they are to be readily sought and incorporated. As Peter Drucker pointed out, effectiveness must precede efficiency. [Drucker 1954]

\section{Cost Driven Diversity}

In this model the underlying thesis is economic - there must be some substantive difference to the firm in the cost of production and revenue generated in the economic exchange process. While connected to skill driven diversity, the distinguishing difference is some groups "can be" or "are willing" to be paid less than others. In the first case, the lower "cost" may be tied to the level of economic development of the group. Specifically, the example is that of diversity associated with another culture (country or segment). Many US firms have moved offshore or have outsourced the creation of their product to countries where raw material input in the form of labor or materials is substantially less. This can also be seen in the relocation of firms within the US, as exampled by relocation from the Northeast or West Coast to the Southern states. Here the firm is able to obtain the same skills at a lower cost and the diverse group is willing to accept a lesser amount than the firm would pay within its home market. On a comparative basis the firm finds it economically justifiable to produce the product where the required task process cost less.

In the second case, the firm finds that within its home market (country), there is an acceptance that performance of certain tasks, grouped into jobs, are "worth" only so much. Those possessing these lower requisite skill levels are often found in the diverse groupings based on such attributes as educational, language skills, age, gender and even ethnic origins. The example is the teenager working at the fast-food restaurant. Such a decisional approach is quite common before government forced changes. Cost driven diversity is exclusive rather than inclusive in its focus.

\section{Ethics Driven Diversity}

An ethically based approach to an incorporation of diversity into the firm is grounded in the premise of it is the right thing to do. Exclusion based on an attribute that is different from the current make-up is to be rejected. This view is beyond that required by law. This approach is tied to the "social responsibility" model of firm behavior. Ethically driven diversity may result in cost escalation. The absence or presence of skill at a lower level is accepted as a cost of doing what "should be done". A balancing feature is tied to the "learning organization" approach. Difference in skill levels can be reduced or eliminated through the leaning process. Firms which accept this social costing must offset the cost in another part of the organization or pass it through to the customer. Here we can see a tie to market driven diversity in terms of a buying group willing to pay extra or forego a higher return 
to achieve this social good. An example often cited is the creation of a mutual fund composed of stock in firms following a social agenda.

The model is culturally bound. Its presence or use may vary substantially among countries reflecting local cultural determinants or in the cultural imperatives brought to bear by outsiders. Firms are faced with the decision to "do as the Romans do" or try and follow home country value sets. For US firms we see this paradox in shifting or outsourcing jobs by some for cost reasons, while others use "illegals" in country to reduce costs. The model may also reflect the changing values and attitudes within the general populace in terms of sustainability and being green/carbon friendly.

\section{De facto Diversity}

By fact, the firm may be (seem to be) diverse in its market approach and workforce make-up simply because the market (customer) and population (workforce source) environments are inherently diverse. There is really no choice. To acquire the necessary labor force with requisite skills, selection is made from the existing market. An example may be the state of Hawaii with its highly diverse multiple ethnic and cultural base. While this may be an espoused view, it is again problematic in trying to find real life examples as the social stratification, norms and mores are deeply embedded, finely separating those within the environment and often unacknowledged by the insider and unrecognizable to an outsider. Strategically, unless firms relocate, diversity and associated costs are borne by all and there is no competitive advantage to be gained.

\section{De jure Diversity}

This is diversity as determined by the social codification of behaviors and values - that is as required by law. All firms must incorporate the legal requirements associated with the treatment of diversity along those attributes so determined. In this view you need not go further than the "law". Absence consideration of the other models collectively or individually the strategic impact is shared by all. Thus "diversity" is not available as a positive competitive feature within the area subject to the law; however, it functions as a hygiene level of diversity with a resulting negative impact if not achieved. It also may present a weakness when compared to legal requirements in other markets.

\section{DISCUSSION}

An "imperative" is defined as a binding or compelling rule, duty, or requirement. [Webster's 2005] In this paper we have seen that diversity can be a strong concept to be addressed by the firm. In some instances it may be a legal requirement. Certainly de jure diversity is a business imperative but not a strategic imperative. In other instances diversity may also be a basic requirement in order to be competitive. And still in other situations there may be no need to really address the concept as it is already an institutionalized force. Whether or not it serves as a basis for strategy to a great extent is dependent on "the how" it serves as a driving force upon the business environment or as a competence in the specific firm. In those cases where diversity in its many forms impacts all and there is the requirement for all to address it, it becomes a common business requirement for all firms. If it is required, then there is little opportunity to make it the "firm's" in a way that provides a competitive advantage. Note, however, that a firm which is unable to effectively incorporate a requirement is placed in a vulnerable position vis-à-vis its competitors.

However, if it is looked at as a source of the skills or understanding which makes it possible to develop or establish a further basis of competition, then it offers the firm something others may not have taken advantage of, or found a way to institutionalize the resulting benefits. Thus, it will come to the old management adage and answer "it depends" as to whether or not it functions as a competency itself or provides just the basis for the development of such an advantage. It is both an end and a means to the firm meeting the multiple constituencies (stakeholders) driving the development of a competitive strategy.

For a strategy to work, it needs to be consistent and in balance with the firm's internal and external environments. It must be operationalized - put into effect. From the preceding we can see that diversity offers 
potentially strong benefits to the organization in structuring itself to address the changing forces outside by changing the inside. Yet the mere presence of a diverse work group may serve no more than meeting the driving forces that are imposed from the outside (Governmental requirements) on all. Without constructive use, a blending of the assets of the workforce, it may serve to divide rather than add a synergistic effect.

For the market, unless the organization is pursuing a strategy looking at a specific homogeneous customer grouping, the diversity of the market demands the examination and inclusion of such diversity within its strategy development. Thus one may say that it is an imperative that diversity be a part of the enunciated strategy. But this can be said of all the competitors in the same marketplace. All are looking essentially at the same consuming group. The broad market is composed of diverse groupings, each to some extent using the product differently while still demanding the common components. Thus it is a basic business requirement.

What we are left with is a paradoxical problem. The Toyota example indicates that a likeminded, tightly constructed culture is key to bringing about the substantive changes to a product and the process; thus, trying to eliminate the variation in approach and outcome while still delivering the same near identical product to their diverse market. The other view is that differences stemming from the diversity of the workforce can be invigorating and the source of new ideas and knowledge. The melding of these two seemingly skewed approaches can be brought about by recognizing that diversity at one level does not mean or carry forth such inherent differences in pursuit of the common goal of the firm. The diverse consuming market provides an over arching commonality. The diverse working population within the firm can likewise be focused on this same need for commonality, putting aside the characteristics that make them different and emphasizing that which binds them together.

The drawing from these differences, the integration of these virtues within the organization to achieve a common goal is required of each firm within the industry structure. It becomes a critical point of vulnerability to the firm which fails to acquire and then use this capability. It thus becomes a competitive imperative. The end result is the imperative that diversity becomes a "basic business requirement". The lingering question then becomes: Will it, like the "quality imperative" of the 1980s result in a bloom and then fade away or will it be institutionalized?

Recognition of "diversity" is a basic business requirement. That which you can't recognize can't be use as a source of competitive strength. The firm's competence in using diversity in terms of one or more of the dimensions identified does provide a strategic building block. Thus, it is not diversity in terms of race, age, etc. that is the competitive weapon, it is the ability or competence the firm possesses to identify the other delimiters of differences and to incorporate those in its business endeavors, both in their strategy determination and its subsequent operationalization.

\section{AUTHOR INFORMATION}

Kenneth R. Tillery is a Professor of Management in the Jennings A. Jones College of Business of Middle Tennessee State University. Dr. Tillery researches and teaches in the areas of strategic management and international business. His non-academic work experience is quite varied, including service within the public and private sectors. He has consulted in the areas of Strategic Management, Business Process Reengineering and Organizational Training. He holds a Ph. D. in Business Administration from Georgia State University.

Arthur L. Rutledge is an Associate Professor of Management in the Stetson School of Business \& Economics at Mercer University where he teaches MIS, operations, and technology management. Dr. Rutledge has consulted extensively in total quality management, business process reengineering, and MIS. Management, Quality, and MIS are his fields of research. His Ph.D. is from Georgia State University.

\section{REFERENCES}

1. Cantrell, Julie, GM creates Diversity Marketing, Sales Unit, Automotive News, 75, 5928, May 7, 2001.

2. $\quad$ Drucker, Peter F., The Practice of Management, Harper \& Brothers Publishers, New York, 1954.

3. Dumont, Elinor, Diversity Marketing Will Soon be the Rule, Bank Marketing, 29, 11, Washington: November 2007. 
4. Harrison, David A., Price, Kenneth H., and Bell, Myrtle P., Beyond Relational Demography; Time and the Effects of Surface and Deep Level Diversity on Work Group Cohesion, Academy of Management Journal, 41, 1, February 1998.

5. Hitt, Michael A., Ireland, R. Duane and Hoskisson, Robert E., Strategic Management; Competitiveness and Globalization, $7^{\text {th }}$ Edition, Thompson South-Western, 2007.

6. McCloskey, Frank, Diversity for Today and Tomorrow, Vital Speeches of the Day. 72, 12, New York: April 1, 2006.

7. Mintzberg, Henry, Five Ps for Strategy, California Management Review, Fall, 1987.

8. Mujtaba, Bahaudin G. and Sungkhawan, Jatuporn, Situational Leadership And Diversity Management Coaching Skills, Journal of Diversity Management, 4, 1, $1^{\text {st }}$ Qtr. 2009.

9. Ohno, Taiichi, "Nippon: Japan Since 1945, Taking on Detroit", 5, VHS, BBC TV, 1990.

10. Porter, Michael E., What is Strategy? Harvard Business Review, 74, 6, Nov-Dec 1996.

11. Richard, Orlando, C., Racial Diversity, Business Strategy, and Firm Performance: A Resource-Based View, Academy of Management Journal, 43, 2, April 2000.

12. Rutledge, Arthur L., Tillery, Kenneth R., A Taxonomy of Social Diversity for Strategic Management, American Society of Business and Behavioral Sciences, $16^{\text {th }}$ Annual Meeting, Las Vegas, February 19-22, 2009.

13. Solomon, Charlene Marmer, Global Operations Demand that HR Rethink Diversity, Personnel Journal, 73 , 7, July 1994.

14. Thomas, David A., Diversity as Strategy, Harvard Business Review, 82, 9, September 2004.

15. Webster's New World College Dictionary (2005), $4^{\text {th }}$ Edition, Wiley Publishing, 2005.

16. D_ Deloitte \& Touche Strengthens Commitment to Diversity with Creation of Advisory Board, PR Newswire. New York: October 7, 2002.

17. _ Borders Group Establishes External Diversity Council. PR Newswire. New York: May 8, 2007. 